\title{
Alexithymia, Emotion Processing and Social Anxiety IN ADUlts with ADHD
}

\author{
M.-A. Edel ${ }^{1}$, A. Rudel ${ }^{1}$, C. Hubert ${ }^{1}$, D. Scheele ${ }^{1}$, M. Brüne ${ }^{1}$, G. Juckel ${ }^{1}$, H.-J. Assion ${ }^{2}$ \\ ${ }^{1}$ Dept. of Psychiatry, Ruhr University, LWL Hospital Bochum, Germany, \\ ${ }^{2}$ gpz - Dept. of Psychiatry, Detmold, Germany
}

\begin{abstract}
Objective: Given sparse research on the issue, this study sought to shed light upon the interactions of alexithymia, emotion processing, and social anxiety in adults with attention-deficit hyperactivity disorder (ADHD).

Subjects and methods: 73 German adults with ADHD according to DSM-IV diagnostic criteria participated. We used the Toronto Alexithymia Scale (TAS-20) to assess alexithymia, the Social Phobia Scale (SPS) and the Social Interaction Anxiety Scale (SIAS) to assess different features of social anxiety, and we applied the German 'Experience of Emotions Scale' (SEE) to measure emotion processing.

Results: $40 \%$ of the sample were found to meet the DSM-IV criteria of social anxiety disorder, and about $22 \%$ were highly alexithymic according to a TAS-20 total score $\geq 61$; however, the mean TAS-20 total score of $50.94 \pm 9.3$ was not much higher than in community samples. Alexithymic traits emerged to be closely linked to emotion processing problems, particularly 'difficulty accepting own emotions', and to social anxiety features.

Discussion/conclusion: Our findings suggest interactions of alexithymia, emotion processing dysfunction, and social anxiety in adults with ADHD, which may entail the therapeutic implication to thoroughly instruct these patients to identify, accept, communicate, and regulate their emotions to aid reducing interaction anxiety.
\end{abstract}

Key words: Attention deficit/hyperactivity disorder adults - TAS-20 - SPS - SIAS - social phobia

\section{INTRODUCTION}

DSM-IV criteria for ADHD comprise symptoms of hyperactivity/restlessness, impulsivity, and inattentiveness (APA, 1994). However, Wender et al. [30] suggested four additional diagnostic categories ('disorganization', 'temper', 'affective lability', and 'emotional overreactivity'), of which three imply emotional dysregulation [21]. Dysfunctional emotion processing in adult ADHD, however, may at least in part result from alexithymia [10]. Alexithymia, literally the "inability to read emotions", is characterized by difficulties identifying and describing own feelings, and an externally oriented cognitive style, related to concrete non-introspective thinking $[11,26]$. Initially being delineated in psychosomatic patients [24], the construct was used increasingly interdisciplinary in the last decades in psychological, neurobehavioral, and clinical research on general population samples $[9,18]$ and in diverse psychiatric conditions [5], particularly depressive [14, 16] and anxiety disorders [17]. More recent investigations focused a connection between alexithymic traits and social anxiety [28], lending support to the idea that difficulties identifying and communicating own emotions may present a major obstacle to social interaction [29]. To close the circle, social anxiety disorder emerged to be a frequent comorbid disorder in adults with ADHD [8]. However, the interaction of alexithymia, emotion processing, and social competence in hyperactive adults has been investigated sparsely [10, 20], and there are no studies on the implications of 'low emotion identification skill' [27] with respect to emotion processing and social anxiety in adult ADHD. Hence, our aim was to assess these features, hypothesizing close associations between the perception and processing of emotions, and social anxiety disorder in adults with ADHD.

\section{SubJECTS AND METHODS}

\section{PARTICIPANTS}

142 German adults from the ADHD outpatient unit of the Dept. of Psychiatry, Ruhr University, Bochum, with the full DSM-IV criteria [1] of ADHD were contacted by mail and requested to participate in the study. 73 patients $(51.4 \%)$ sent back complete questionnaires and gave full informed consent.

The sample comprised 34 female $(46.6 \%)$ and 39 male $(53.4 \%)$ individuals with a mean age of $40 \pm 9.7$ years (range 18-66); there were no significant age differences between females and males $(t=0.33$; $d f=$ 61.07; $P=0.74)$. Less than one third $(30.5 \%)$ of the subjects had a higher education entrance qualification or an university degree; no significant gender difference emerged with respect to graduation levels (MannWhitney $U=551 ; P=0.26)$. 40 of the subjects (54.8\%) had been diagnosed ADHD combined type, $33(45.2 \%)$ had been given the diagnosis of ADHD predominantly inattentive type according to DSM-IV criteria; with ADHD subtypes we did not find any 
gender differences, either $\left(\chi^{2}=1.24 ; d f=1 ; P=0.27\right)$. 21 subjects $(28.8 \%)$ of the sample were unmedicated, $15(20.5 \%)$ were on antidepressants with catecholaminergic properties only, $23(31.5 \%)$ were treated with methylphenidate alone, and $14(19.2 \%)$ received a combination of methylphenidate with an antidepressant. Antidepressants were reboxetine $2-6 \mathrm{mg} / \mathrm{d}$, venlafaxine 37,5-150 mg, duloxetine 30-90 mg/d, and bupropion 150-300 mg/d; methylphenidate dosage was $24.42 \pm 10.94 \mathrm{mg} / \mathrm{d}$.

Gender differences were found neither regarding norepinephrine reuptake inhibitors $\left(\chi^{2}=2.07\right.$; $d f=1$; $P=0.15)$ nor regarding methylphenidate $\left(\chi^{2}=1.22\right.$; $d f=1 ; P=0.27$ ), but there was a trend for patients with ADHD combined type having been treated more frequently with methylphenidate solely than subjects with ADHD predominantly inattentive type $\left(\chi^{2}=\right.$ 5.31; $d f=1 ; P=0.021)$. No significant differences between ADHD subtypes emerged regarding age $(t=$ $0.77 ; d f=63.80 ; P=0.44)$, education $(t=1.18 ; d f=$ 69.63; $P=0.24)$, or gender $\left(\chi^{2}=1.25 ; d f=1 ; P=\right.$ $0.26)$. The mean number of comorbid axis-I disorders was $1.57 \pm 1.04$ (range $0-4$ ), the mean number of comorbid axis-II disorders was $1.60 \pm 1.18$ (range 0-3); no gender differences emerged as to the frequencies of additional axis-I or axis-II comorbidity $(t=-0.85$; $d f=68 ; P=0.39 ; t=0.04 ; d f=68 ; P=0.97$. Main axis-I disorders were anxiety disorders, and, to a lesser extent affective disorders and substance misuse; Cluster $\mathrm{C}$ personality disorders, mainly obsessive compulsive and avoidant personality disorder, were more frequent than Cluster B disorders.

\section{Assessment of Alexithymia And Emotion PROCESSING}

Alexithymia was assessed using the Toronto Alexithymia Scale (TAS-20), a self-report questionnaire containing 20 items rated on a 5 -point scale, yielding possible total scores ranging from 20 to 100 . TAS-20 includes three components: [1] difficulty identifying feelings ("I am often confused about what emotion I am feeling"; "when I am upset, I don't know if I am sad, frightened or angry"), [2] difficulty communicating feelings to others " $\mathrm{I}$ find it hard to describe how I feel about people"; "I am able to describe my feelings easily"), and [3] externally oriented thinking ("I find examination of my feelings useful in solving personal problems"; "I prefer to watch 'light' entertainment shows rather than psychological dramas"). The measure has shown high internal consistency, good testretest reliability, and convergent, discriminant and concurrent validity $[2,3]$. Bagby and Taylor [4] preliminary suggested a TAS-20 total score of $\geq 61$ to indicate high alexithymia. According to this we divided the sample into a higher alexithymia group and a lower alexithymia group. Furthermore, we used the German SEE ("Skala zum Erleben von Emotionen", best translated "Experience of Emotions Scale"), a self-report instrument which allows the registration of a subject's attitude towards his or her own emotions, and the assessment of several emotion processing manners. That questionnaire comprises 42 items and 7 subscales: 1. 'acceptance of own emotions'; 2. 'experi- ence of being flooded with emotions'; 3. 'experience of lack of emotions'; 4. 'physical symbolization of emotions'; 5. 'imaginative symbolization of emotions'; 6. 'experience of emotion regulation'; 7. 'experience of self-control'. SEE has shown good internal consistency, very good test-retest reliability, and entirely satisfactory convergent, discriminant and concurrent validity [7].

\section{Assessment of ADHD, Social Phobia And OTHER AXIS-I DISORDERS}

Diagnoses of ADHD were established while patients were drug-naïve, using the Wender Utah Rating Scale (German WURS-k) [22] to retrospectively assess childhood ADHD symptoms, and an interviewer-rating instrument to assess DSM-IV criteria for an ADHD in adulthood [23]. To measure ADHD symptom extent we summarized DSM-IV A-criterion ADHD symptoms [scale 0-10] within each of the ADHD symptom domains (i.e., inattentiveness=symptom 1-9; hyperactivity=symptom 10-15; impulsivity= symptom 16-18).

The diagnosis of social phobia was made using the International Diagnostic Checklist for DSM-IV (IDCL) [12]. For all other axis-I diagnoses, and for axis-II diagnoses, we used the German version of the SCID-I/II [31]. To measure two distinct features of social anxiety, we applied the German version [25] of the Social Phobia Scale (SPS) [15] and the German version [25] of the Social Interaction Anxiety Scale (SIAS) [15] during treatment process. SPS is a self-rating instrument with 20 dimensional items [0 = strongly disagree; 1 = disagree; $2=$ neither agree nor disagree; $3=$ agree; $4=$ strongly agree] which records fears of an individual to be in the focus of attention of other persons who might negatively appraise the individual's social performance such as public speaking, eating or writing (e.g., "I can get tense when I speak in front of other people"). The internal validity (Cronbach's $\alpha=0.94$ ) of the SPS in patients with social phobia and its test-retest reliability $(r=0.96$ after three weeks) were high [25]. Mean SPS score within a larger group of sociophobic subjects was 28.6 versus 6.8 in healthy controls (mean SPS score in patients with depressive and anxiety disorders was 19.1; with pure depressive disorder: 15.9; with sole anxiety disorder: 13.6). Stangier et al. [25] suggested a cut-off of 22 to separate individuals with social phobia from patients with other disorders within a clinical collective. In addition, SIAS, also consisting of 20 dimensional items (see above), and also yielding high internal validity (Cronbach's $\alpha=0.94$ ) and test-retest reliability ( $r=$ 0.92 after three weeks), was used to assess anxiety in situations of social interaction, in which conversations with friends, strangers or possible partners have to be initiated and maintained (e.g., "I am tense mixing in a group"). Mean SIAS score within a larger group of individuals with social phobia was 48.8 versus 12.5 in healthy controls (mean SIAS score in patients with depressive and anxiety disorders was 30.2; with sole depressive disorder: 28.0; with sole anxiety disorder: 21.6). Stangier et al. [25] suggested a cut-off of 33 to separate individuals with social phobia from patients with other disorders within a clinical collective. 


\section{STATISTiCAl ANALYSES}

Statistical analyses were carried out using SPSS version 12.0 for Windows. We applied t-tests for equality of means (independent samples tests) to analyze gender differences regarding TAS-20, SEE, SPS and SIAS. A MANCOVA was conducted in order to compare subjects with ADHD plus social phobia and pure ADHD regarding SEE scales while eliminating confounding effects of methylphenidate and antidepressive medication. Differences in TAS-20, SPS and SIAS between these two groups were analyzed with an ANCOVA. One-sample Kolmogorov-Smirnov test yielded normal distribution of all residuals except for SPS. To parallel non-metric data (education) resp. to confirm the results of an ANOVA with not normaly distributed errors (SPS) we used the Mann-Whitney U-test. Furthermore, Pearson's correlations were computed for metric data. Chi-square test was applied to examine the frequency distribution of dichotomic variables (i.e., gender, occurrence of social phobia, and ADHD subgroup). Because of multiple testing only results with a significance level at $\mathrm{P}<0.01$ were interpreted. Two-tailed significance tests were conducted because no a-priori hypothesis was stated regarding the direction of differences.

\section{RESULTS}

\section{Gender Differences Regarding TAS-20, SEE,} SPS, AND SIAS

A trend for greater 'experience of lack of emotions' (as measured using the SEE) was found in the male participants $(13.63 \pm 4.39$ vs. $11.12 \pm 3.94 ; t=2.55 ; d f$ $=70 ; P=0.013)$; no gender differences emerged concerning any other scale.

\section{TAS-20 SCORES}

The mean 'difficulty identifying feelings' scale score was $18.06 \pm 6.31$, the mean 'difficulty communicating feelings' scale score was $13.32 \pm 4.56$, the mean 'externally oriented thinking' scale score was $19.57 \pm 4.61$, and the mean TAS-20 total score was $50.94 \pm 11.77$. 16 of 72 subjects $(22.2 \%), 8$ women and 8 men, showed a TAS-20 total score $\geq 61$ indicating high alexithymia.

\section{SEE SCORES}

Mean SEE subscores (with standard deviations) were: 20.44 ( \pm 4.61) for the 'acceptance of own emotions' scale, 23.06 ( \pm 6.85) for the 'experience of being flooded with emotions' scale, 12.44 ( \pm 4.34) for the 'experience of lack of emotions' scale, 25.67 ( \pm 6.50) for the 'physical symbolization of emotions' scale, $15.47( \pm 6.05)$ for the imaginative symbolization of emotions' scale, $11.67( \pm 3.18)$ for the 'experience of emotion regulation’ scale, and 17.21 ( \pm 4.21) for the 'experience of self-control' scale.

\section{Prevalence of Social AnXiety Disorder, AND SPS} AND SIAS IN THE TOTAL SAMPLE

27 (15 women, 12 men) of 68 adult ADHD patients had comorbid social phobia (39.7\%). Mean SPS score was 19.90 ( \pm 16.36), and mean SIAS score was 27.51 $( \pm 16.84)$.

\section{Correlations Between TAS-20 AND SEE SCALES}

The 'difficulty identifying feelings' scale (TAS-20) correlated positively $(r=0.64)$ with the 'experience of being flooded with emotions' scale (SEE), positively ( $\mathrm{r}=$ 0.44) with the 'experience of lack of emotions' (SEE), negatively ( $\mathrm{r}=-0.62)$ with the 'acceptance of own emotions' scale (SEE), and negatively $(r=-0.33)$ with the 'experience of self-control' scale (SEE). The 'difficulty communicating feelings' scale (TAS-20) correlated positively $(\mathrm{r}=0.38)$ with the 'experience of being flooded with emotions' scale (SEE), positively ( $\mathrm{r}=$ $0.64)$ with the 'experience of lack of emotions' scale (SEE), and negatively ( $\mathrm{r}=-0.61)$ with the 'acceptance of own emotions' scale (SEE). The TAS-20 total scores correlated positively $(r=0.45)$ with the 'experience of being flooded with emotions' scale (SEE), positively $(\mathrm{r}=0.60)$ with the 'experience of lack of emotions' scale (SEE), and negatively ( $\mathrm{r}=-0.63$ ) with the 'acceptance of own emotions' scale (SEE) (Table 1).

Table 1. Correlations between TAS-20 and SEE scales.

\begin{tabular}{|c|c|c|c|c|}
\hline & $\begin{array}{c}\text { Acceptance of own } \\
\text { emotions (SEE) }\end{array}$ & $\begin{array}{c}\text { Experience of being } \\
\text { flooded with emotions } \\
\text { (SEE) }\end{array}$ & $\begin{array}{l}\text { Experience of lack } \\
\text { of emotions (SEE) }\end{array}$ & $\begin{array}{c}\text { Experience of } \\
\text { self-control (SEE) }\end{array}$ \\
\hline $\begin{array}{l}\text { Difficulty identifying } \\
\text { feelings } \\
\text { (TAS-20) }\end{array}$ & $-0.62 * *$ & $0.64 * *$ & $0.44 * *$ & $-0.33 * *$ \\
\hline $\begin{array}{l}\text { Difficulty communicating } \\
\text { feelings } \\
\text { (TAS-20) }\end{array}$ & $-0.61 * *$ & $0.38^{* *}$ & $0.64 * *$ & n.s. \\
\hline TAS-20 total score & $-0.63^{* *}$ & $0.45^{* *}$ & $0.60 * *$ & n.s. \\
\hline
\end{tabular}

** $\mathrm{p}<0.01$; n.s. $=$ not significant; TAS $=$ Toronto Alexithymia Scale; SEE = Skala zum Erleben von Emotionen (Experience of Emotions Scale). 
Table 2. Correlations between SPS/SIAS and TAS-20/SEE scales.

\begin{tabular}{lcccccc}
\hline & $\begin{array}{c}\text { Difficulty } \\
\text { identifying } \\
\text { feelings } \\
\text { (TAS-20) }\end{array}$ & $\begin{array}{c}\text { Difficulty } \\
\text { communicating } \\
\text { feelings } \\
\text { (TAS-20) }\end{array}$ & $\begin{array}{c}\text { TAS-20 } \\
\text { total score }\end{array}$ & $\begin{array}{c}\text { Acceptance } \\
\text { of own } \\
\text { emotions } \\
\text { (SEE) }\end{array}$ & $\begin{array}{c}\text { Experience } \\
\text { of being } \\
\text { flooded by } \\
\text { emotions (SEE) }\end{array}$ & $\begin{array}{c}\text { Experience } \\
\text { of lack of } \\
\text { emotions } \\
\text { (SEE) }\end{array}$ \\
\hline SPS & $0.59^{* *}$ & n.s. & $0.38^{* *}$ & $-0.43^{* *}$ & $0.43^{* *}$ & $0.32^{* *}$ \\
SIAS & $0.60^{* *}$ & $0.50^{* *}$ & $0.56^{* *}$ & $-0.48^{* *}$ & $0.36^{* *}$ & $0.46^{* *}$ \\
\hline
\end{tabular}

** $\mathrm{p}<0.01$; n.s. $=$ not significant; TAS $=$ Toronto Alexithymia Scale; SEE = Skala zum Erleben von Emotionen (Experience of Emotions Scale), SPS = Social Phobia Scale; SIAS = Social Interaction Anxiety Scale.

\section{CORRELATIONS BETWEEN SPS/SIAS AND TAS- 20/SEE SCALES}

SPS correlated positively $(\mathrm{r}=0.59)$ with the 'difficulty identifying feelings' scale (TAS-20), positively ( $\mathrm{r}=$ $0.38)$ with the TAS-20 total scale score, positively $(\mathrm{r}=0.43)$ with the 'experience of being flooded by emotions' scale (SEE), positively $(r=0.32)$ with the 'experience of lack of emotions' scale (SEE), nd negatively $(r=-0.43)$ with the 'acceptance of own emotions' scale (SEE). SIAS correlated positively $(\mathrm{r}=0.60)$ with the 'difficulty identifying feelings' scale (TAS-20), positively $(\mathrm{r}=0.50)$ with the 'difficulty communicating feelings' scale (TAS-20), positively ( $\mathrm{r}$ $=0.36$ ) with the 'experience of being flooded by emotions' scale (SEE), positively $(r=0.46)$ with the 'experience of lack of emotions'scale (SEE), and negatively $(r=-0.48)$ with the 'acceptance of own emotions' scale (SEE) (Table 2).

\section{ADHD Plus Social Phobia vs. ADHD ONLY REGARDING TAS-20 AND SEE SCORES}

When controlling for methylphenidate and antidepressive medication, no statistically significant differences emerged regarding TAS-20 and SEE scores between subjects with comorbid social anxiety and those with pure ADHD. However, there was a trend for a higher 'difficulty identifying feelings' scale score in the comorbid patients $(20.37 \pm 6.41$ vs. $16.95 \pm 6.11$; F1, 63 $=5.1, \mathrm{P}=0.03$.

\section{Group Differences Regarding Non-SCALE VARIABLES}

Individuals in the group with higher alexithymia $(\geq 61)$ did not show any statistical differences with respect to ADHD symptom extent (as to inattentiveness, hyperactivity, and impulsivity), number of axis-I other than social phobia, and axis-II disorders, and age, compared to the lower alexithymia group (TAS-20 total score $<$ 61). The diagnosis of social anxiety disorder was not found to be overrepresented in the high alexithymia group $\left(\chi^{2}=0.822, d f=1, P=0.365\right)$ and the level of education was comparable in both groups (MannWhitney-U $=396.5, P=0.52)$. The ADHD subtype $\left(\chi^{2}=0.96 ; d f=1 ; P=0.757\right)$ and gender ratios were also equivalent between groups $\left(\chi^{2}=0.064, d f=1, P\right.$ $=0.801)$.

Group DifFERENCES (TAS-20 TOTAL SCORE < 61 vS. $\geq 61)$ REgARDing SEE, SPS, AND SIAS SCORES

The scores of subjects with high and low alexithymia are shown in Table 3 and also depicted in Fig. 1. When controlled for methylphenidate and antidepressive medication by means of a MANCOVA the SEE scales differed significantly between subjects with high and low alexithymia $\left(F_{7 ; 61}=3.77, P<0.01\right)$. The differentiation between high and low alexithymia accounted for $30 \%$ of the variance of the SEE scales. An ANCOVA revealed that the high alexithymia group displayed significantly less 'acceptance of own emotions' (SEE; $16.56 \pm 4.76$ vs. $\left.21.55 \pm 3.94 ; F_{1 ; 67}=18.69, P<0.01\right)$,

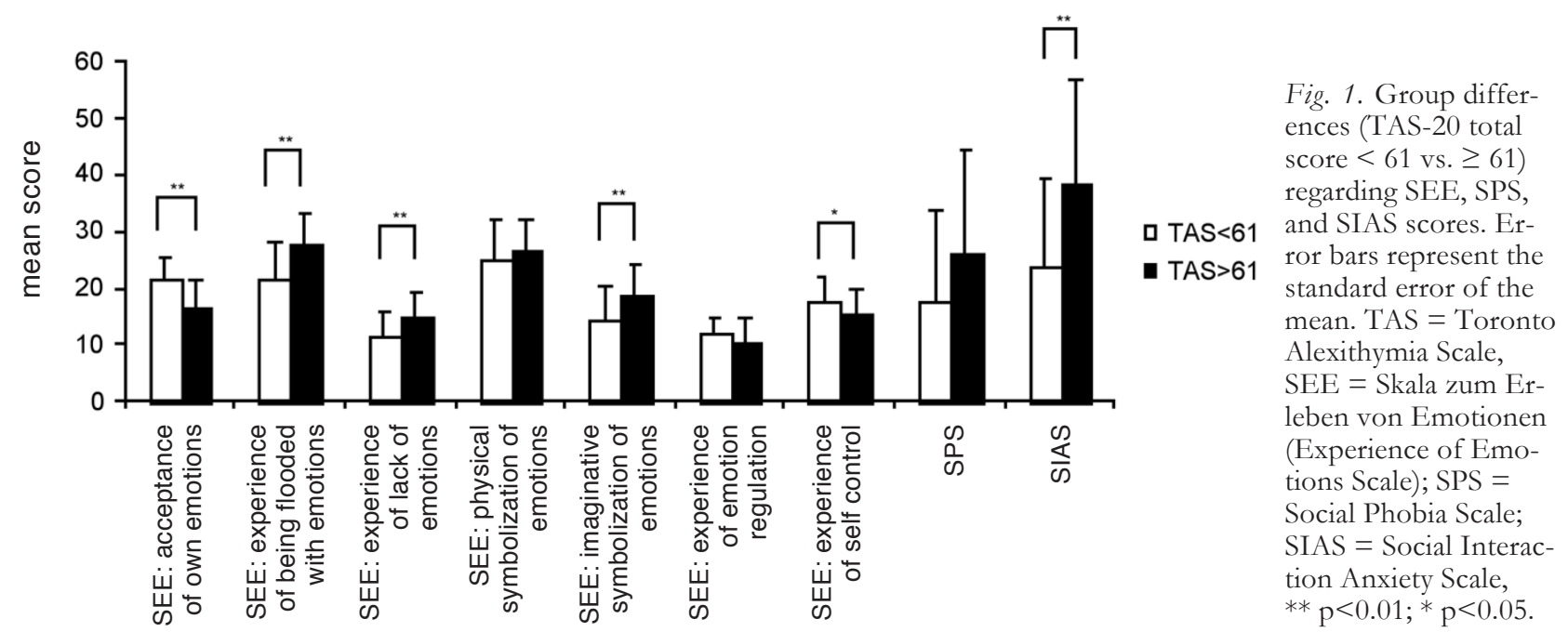


Table 3. Group differences (TAS-20 total score < 61 vs. $\geq 61$ ) regarding SEE, SPS, and SIAS scores.

\begin{tabular}{|c|c|c|c|c|c|}
\hline Test dimension & $\begin{array}{l}\text { TAS-20 total score } \\
\quad<61(\mathrm{n}=56) 1\end{array}$ & $\begin{array}{l}\text { TAS-20 total score } \\
\geq 61(\mathrm{n}=16) 1\end{array}$ & $\begin{array}{c}\text { MANCOVA/ } \\
\text { ANCOVA }^{2} \\
F\end{array}$ & $\mathrm{p}$ & $\eta^{2}$ \\
\hline SEE & & & 3.77 & $<0.01$ & 0.30 \\
\hline $\begin{array}{l}\text { acceptance of own } \\
\text { emotions }\end{array}$ & $21.55(3.98)$ & $16.56(4.76)$ & 18.69 & $<0.01$ & 0.22 \\
\hline $\begin{array}{l}\text { experience of being } \\
\text { flooded with emotions }\end{array}$ & $21.82(6.66)$ & $27.75(5.48)$ & 10.33 & $<0.01$ & 0.13 \\
\hline $\begin{array}{l}\text { experience of lack of } \\
\text { emotions }\end{array}$ & $11.75(4.2)$ & $15.13(3.86)$ & 7.9 & $<0.01$ & 0.11 \\
\hline $\begin{array}{l}\text { physical } \\
\text { symbolization of } \\
\text { emotions }\end{array}$ & $25.35(6.87)$ & $26.94(5.28)$ & 0.8 & 0.37 & 0.01 \\
\hline $\begin{array}{l}\text { imaginative } \\
\text { symbolization } \\
\text { of emotions }\end{array}$ & $14.47(6.02)$ & $18.88(5.14)$ & 8.05 & $<0.01$ & 0.11 \\
\hline $\begin{array}{l}\text { experience of } \\
\text { emotion regulation }\end{array}$ & $11.95(2.87)$ & $10.63(4.06)$ & 1.97 & 0.16 & 0.03 \\
\hline $\begin{array}{l}\text { experience of self- } \\
\text { control }\end{array}$ & $17.78(4.01)$ & $15.31(4.54)$ & 4.48 & 0.04 & 0.06 \\
\hline SPS & $18.35(15.52)$ & $26.19(18.14)$ & 2.71 & 0.11 & 0.04 \\
\hline SLAS & $24.48(15.19)$ & $38.81(17.86)$ & 8.82 & $<0.01$ & 0.13 \\
\hline
\end{tabular}

${ }^{1}$ Values are expressed as mean (SD); ${ }^{2}$ with methylphenidate and antidepressive medication as covariate; TAS = Toronto Alexithymia Scale; MANCOVA = multivariate analysis of covariance; ANCOVA = analysis of covariance; SEE = Skala zum Erleben von Emotionen (Experience of Emotions Scale); SPS = Social Phobia Scale; SIAS = Social Interaction Anxiety Scale.

significantly more 'experience of being flooded with emotions' (SEE; $27.75 \pm 5.48$ vs. $21.71 \pm 6.64 ; F_{1 ; 67}=$ $10.33, P<0.01)$, significantly more 'experience of lack of emotions' (SEE; $15.12 \pm 3.86$ vs. $11.68 \pm 4.19 ; F_{1: 67}$ $=7.9, P<0.01)$, significantly more 'imaginative symbolization of emotions' (SEE; $18.87 \pm 5.14$ vs. 14.50 \pm 5.97; $F_{1 ; 67}=8.05, P<0.01$ ), significantly less 'experience of self-control' (SEE; $15.31 \pm 4.54$ vs. $17.78 \pm$ 4.01; $\left.F_{1 ; 67}=4.48, P<0.05\right)$ and a significantly higher SIAS score $\left(38.81 \pm 17.86\right.$ vs. $24.22 \pm 15.18 ; F_{1 ; 66}=$ 9.82, $P<0.01)$ than the non-alexithymia group. A partial eta squared of 0.22 indicated that the group differences with acceptance of own emotions were the most important one.

\section{DISCUSSION}

A considerable rate of highly alexithymic adults $(22.2 \%$ with a TAS-20 total score $\geq 61)$ was identified in the sample of this study and the mean TAS-20 total score was 50.94 ( \pm 11.77). For comparison, Franz et al. [9] reported a mean TAS-20 total score of 49.5 ( \pm $9.3)$ in men and $48.2( \pm 9.3)$ in women within a representative random sample of the German general population comprising 1859 subjects. These findings do not differ grossly from the mean TAS-20 total value in our clinical sample. However, compared to our results,
Franz et al. detected only about half the portion of highly alexithymic individuals, 99 men $(5.3 \%)$ and 86 women $(4.6 \%)$. Within a large community sample $(\mathrm{n}=$ 1933) Parker et al. [18] found mean TAS-20 values of $45.57 \pm 11.35$ (total score), $14.38 \pm 5.21$ ('difficulty identifying feelings'), $12.50 \pm 4.20$ ('difficulty describing feelings'), and $18.70 \pm 4.72$ ('externally oriented thinking'). Our results contrast these findings with respect to a moderately higher TAS-20 total score (see above) and a moderately higher 'difficulty identifying feelings' score $(18.06 \pm 6.31)$ in adults with ADHD which may indicate a specific emotion processing difficulty in these individuals. The TAS-20 total score of our subjects was of comparable magnitude as Friedman et al. [10] found in 21 adults with ADHD (50.5 \pm 11.9).

Compared to a German random community sample [7], mean SEE values in this study were in a medium range as to 'experience of being flooded with emotions', 'physical symbolization of emotions', 'imaginative symbolization of emotions', and 'experience of emotion regulation'. In contrast, 'acceptance of own emotions' and 'experience of self-control' values were in a low range, and mean 'experience of being flooded with emotions' score was in a high range. These findings are in accordance with the results of Rapport et al. [20] who reported ADHD adults to experience a 
greater intensity of emotions than normal controls. Moreover, 'low experience of self-control' may reflect general inhibitory deficits in adults with ADHD [6]. To our knowledge, the issue of low 'acceptance of own emotions' in adult patients with ADHD has not yet been reported explicitly. However, mindful acceptance of own emotions is one of the crucial aims of Dialectical Behavioral Therapy (DBT) developed by M. Linehan [13], a structured skills training program, combining cognitive behavioral approaches with meditation techniques to enhance mindfulness. This concept has been adapted to the treatment of adults with ADHD [11, 19]. Lack of 'acceptance of own emotions' was associated with alexithymia, due to higher correlations with 'difficulty identifying feelings' and 'difficulty describing feelings', but not due to 'externally oriented thinking'. However, 'difficulty identifying feelings' was rather associated with 'experience of being flooded with emotions', and 'difficulty communicating feelings' was rather linked to 'experience of lack of emotions', relations that ought to be studied further in order to comprehend the complexity of affect recognition, emotion processing and social behavior in adults with ADHD; for instance, it remains to be clarified whether the experience of being flooded with emotions is rather a consequence of an alexithymic trait indicating difficulties in identifying own feelings, or provoke difficulties in identifying feelings as an alexithymic state. Analogously, the causality between difficulties describing or communicating feelings and the experience of lack of emotions ought to be investigated.

The prevalence of social anxiety was about $40 \%$ in our sample. Mean SPS and SAIS values were in about the ranges of those patients with combined depression and anxiety according to Stangier et al. [25]. Both social anxiety scales were associated with several items of TAS-20 and SEE scales, indicating close ties between social anxiety on the one hand, and alexithymia (particularly 'difficulty identifying feelings') and other emotion processing features (particularly 'acceptance of own emotions') on the other hand.

The highly alexithymic subjects in our sample displayed significantly fewer 'acceptance of emotions', fewer 'experience of self-control' and more 'experience of being flooded with emotions', more 'experience of lack of emotions', more 'imaginative symbolization of emotions', and more social interaction anxiety.

\section{CONCLUSION}

These findings confirm our proposition of an interaction of alexithymia, acceptance of own emotions, the strain of a distorted emotionality (i.e., too intensive or too sparse feelings, respectively), and social anxiety in adults with ADHD. We particularly suggest that alexithymia may be a major risk factor for emotion regulation deficits in adult ADHD, and social anxiety disorder be a possible sequela of such emotion processing dysfunction. Diagnostic procedures in adults with ADHD should therefore consider the respective relationship of emotion processing and social interaction, especially since ADHD is not simply a matter of cognitive deficits.
Therapeutic implications may be to thoroughly instruct adults with ADHD to identify, accept, regulate, and communicate own emotions to limit the risk of interaction anxiety. Particularly the mindfulness-based structured skills training for adult ADHD constructed by colleagues in Freiburg [11,19] may encourage patients to accept own feelings in order to handle and communicate them adequately. As a result social interaction problems including social anxiety could be reduced.

To address the limitations of our study, we used a retrospective design and data assessment was mainly based on self-rating instruments.

\section{REFERENCES}

1. American Psychiatric Association. Diagnostic and statistical manual of mental disorders (4th Edition) Washington D.C.: American Psychiatric Press; 1994

2. Bagby RM, Taylor GJ, Parker JD. The twenty-item Toronto Alexithymia Scale -I. Item selection and crossvalidation of the factor structure. J Psychosom Res 1994; 38:23-32

3. Bagby RM, Parker JD, Taylor GJ. The twenty-item Toronto Alexithymia Scale -II. Convergent, discriminant, and concurrent validity. J Psychosom Res 1994;38:33-40

4. Bagby M, Taylor G. Measurement and validation of the alexithymia construct. In: Taylor GJ, Bagby RM, Parker JDA, editors Disorders of affect regulation. Cambridge, University Press; 1997

5. Bankier B, Aigner M, Bach M. Alexithymia in DSM-IV disorder - comparative evaluation of somotoform disorder, panic disorder, obsessive-compulsive disorder, and depression. Psychosomatics 2001;42:235-40

6. Barkley RA. Behavioral inhibition, sustained attention, and executive functions: Constructing a unifying theory of ADHD. Psychological Bulletin 1997;121:65-94

7. Behr, M., Becker, M. Skalen zum Erleben von Emotionen (SEE) Göttingen, Hogrefe; 2004

8. Biederman J, Faraone SV, Spencer T, Wilens T, Norman D, Lapey KA, Mick EM, Krifcher Lehman B, Doyle A. Patterns of psychiatric comorbidity, cognition, and psychosocial functioning in adults with attention deficit hyperactivity disorder. Am J Psychiatry 1993;150:1792-98

9. Franz M, Popp K, Schaefer F, Sitte W, Schneider C, Hardt J, Decker O, Braehler E. Alexithymia in the German general population. Soc Psychiatry Psychiatr Epidemiol 2008;43:54-62

10. Friedman SR, Rapport LJ, Lumley M, Tzelepis A, VanVoorhis A, Stettner L, Kakaati L. Aspects of social and emotional competence in adult attention-deficit/hyperactivity disorder. Neuropsychology 2003;17:50-8

11. Hesslinger B, Tebartz von Elst L, Nyberg E, Dykierek P, Richter H, Berner M, Ebert D. Psychotherapy of attention deficit hyperactivity disorder in adults - a pilot study using a structured skills training program. Eur Arch Psychiatry Clin Neurosci 2002;252:177-84

12. Hiller W, Zaudig M, Mombour W. Internationale Diagnosen Checklisten (IDCL) für DSM-IV. Göttingen, Bern: Hogrefe; 1997

13. Linehan M. Skills Training Manual for Treating Borderline Personality Disorder. The Guilford Press, New York; 1993

14. Loas G, Dhee-Perot P, Chaperot C, Fremaux D, Gayant C, Boyer P. Anhedonia, alexithymia and locus of control in unipolar major depressive disorders. Psychopathology 1998;31:206-12

15. Mattick RP, Clarke JC (1989) Development and validation of measures of social phobia scrutiny fear and social interaction anxiety. Behav Res Ther 20: 2-23 
16. Parker JDA, Taylor GJ, Bagby RM. Alexithymia and depression: distinct or overlapping constructs? Compr Psychiatry 1993;32:387-94

17. Parker JDA, Taylor GJ, Bagby RM, Acklin MW. Alexithymia in panic disorder and simple phobia: a comparative study. Am J Psychiatry 1993;150:1105-7

18. Parker JDA, Taylor GJ, Bagby RM. The 20-item Toronto Alexithymia Scale - III. Reliability and factorial validity in a community population. J Psychosom Res 2003;55:26975

19. Philipsen A, Richter H, Peters J, Alm B, Sobanski E, Colla M, Münzebrock M, Scheel C, Jacob C, Perlov E, Tebartz van Elst L, Hesslinger B. Structured group psychotherapy in adults with attention deficit hyperactivity disorder: results of an open multicentre study. J Nerv Ment Dis 2007;195:1013-19

20. Rapport LJ, Friedman SL, Tzelepis A, Van Voorhis A. Experienced emotion and affect recognition in adult attention-deficit hyperactivity disorder. Neuropsychology 2002;16:102-10

21. Reimherr FW, Marchant BK, Strong RE, Hedges DW, Adler L, Spencer TJ, West SA, Soni P. Emotional dysregulation in adult ADHD and response to atomoxetine. Biol Psychiatry 2005;58:125-131

22. Retz-Junginger P, Retz W, Blocher D, Weijers HG, Trott GE, Wender PH, Rösler $M$. Wender Utah rating scale. The short-version for the assessment of the attentiondeficit hyperactivity disorder (German). Nervenarzt 2002;73:830-38

23. Rösler M, Retz W, Retz-Junginger P, Thome J, Supprian T, Nissen T, Stieglitz RD, Blocher D, Hengesch G, Trott GE. Tools fort he diagnosis of attention-deficit/hyperactivity disorder in adults. Self-rating behaviour questionnaire and diagnostic checklist (German). Nervenarzt 2004;75:888-95

24. Sifneos PE. The prevalence of alexithymic characteristics in psychosomatic patients. Psychother Psychosom 1973;22:255-62
25. Stangier U, Heidenreich T, Peitz M, Lauterbach W, Clark DM. Die Erfassung sozialer Phobie durch die Social Interaction Anxiety Scale (SIAS) und die Social Phobia Scale (SPS). Zeitschrift für Klinische Psychologie 1999;28:28-36

26. Taylor GJ, Bagby RM. An overview of the alexithymia construct. In: Baron R, Parker JDA (eds.) Handbook of Emotional Intelligence. San Francisco, Jossey-Bass; 2000. p. $40-7$

27. Taylor GJ, Bagby RM. New trends in alexithymia research. Psychother Psychosom 2004;73:68-77

28. Turk CL, Heimberg RG, Luterek JA, Mennin DS, Fresco DM. Emotion dysregulation in generalized anxiety disorder: a comparison with social anxiety disorder. Cognit Ther Res 2005;29:89-106

29. Vanheule S, Desmet M, Meganck R, Bogaerts S. Alexithymia and interpersonal problems. J Clin Psychol 2007;63:109-17

30. Wender PH, Reimherr FW, Wood DR. Attention deficit disorder ('minimal brain dysfunction') in adults: A replication study of diagnosis and drug treatment. Arch Gen Psychiatry 1981;38:449-56

31. Wittchen HU, Wunderlich U, Gruschwitz S, Zaudig M. Strukturiertes Interview für DSM-IV (SKID). Göttingen: Hogrefe; 1997

Received: December 11, 2009 / Accepted: July 7, 2010

Address for correspondence:

Hans-Jörg Assion, MD

gpz - Dep. of Psychiatry, Psychotherapy

and Psychosomatic Medicine

Schlabrendorffweg 2-6

32756 Detmold

Germany

Phone: +49-5231-45850900

Fax: +49-5231-45850-805

E-mail: assion-hj@versanet.de 